\title{
Orthographic facilitation and phonological inhibition in spoken word recognition: A developmental study
}

\author{
Johannes C. Ziegler and Mathilde MuneauX \\ CNRS and Université de Provence, Marseille, France
}

\begin{abstract}
We investigated the extent to which learning to read and write affects spoken word recognition. Previous studies have reported orthographic effects on spoken language in skilled readers. However, very few studies have addressed the development of these effects as a function of reading expertise. We therefore studied orthographic neighborhood $(\mathrm{ON})$ and phonological neighborhood $(\mathrm{PN})$ effects in spoken word recognition in beginning and advanced readers and in children with developmental dyslexia. We predicted that whereas both beginning and advanced readers would show normal PN effects, only advanced readers would show ON effects. The results confirmed these predictions. The size of the ON effect on spoken word recognition was strongly predicted by written language experience and proficiency. In contrast, the size of the PN effect was not affected by reading level. Moreover, dyslexic readers showed no orthographic effects on spoken word recognition. In sum, these data suggest that orthographic effects on spoken word recognition are not artifacts of some uncontrolled spoken language property but reflect a genuine influence of orthographic information on spoken word recognition.
\end{abstract}

Literacy seems to affect spoken language processing (Ben-Dror, Frost, \& Bentin, 1995; Castles, Holmes, Neath, \& Kinoshita, 2003; Hallé, Chéreau, \& Segui, 2000). Most of this evidence comes from metaphonological tasks. For example, rhyme judgments are easier for word pairs that are spelled similarly (tie/pie) than for word pairs that are spelled differently (tie/rye - see Seidenberg \& Tanenhaus, 1979). Most strikingly, illiterate people find it very difficult to delete a phoneme at the beginning or at the end of a nonword, which suggests that literacy changes our capacity to reflect upon spoken language (Morais, Cary, Alegria, \& Bertelson, 1979).

More recently, it has been shown that literacy affects not only metaphonological tasks but also online spoken word recognition (see, e.g., Chéreau, Gaskell, \& Dumay, 2007; Slowiaczek, Soltano, Wieting, \& Bishop, 2003). One of the most clear-cut demonstrations comes from a study by Ziegler and Ferrand (1998). Using a simple auditory lexical decision task, they showed that English words with phonological rhymes that had ambiguous (inconsistent) spellings (e.g., /ip/, which may be spelled eap or eep, as in leap and deep) produced slower responses than words with unambiguous (consistent) spellings (e.g., $/ \Lambda \mathrm{k} /$, which may only be spelled $u c k$, as in $d u c k$ ). Because the conscious use of orthographic knowledge offered participants no advantage in succeeding at the task, Ziegler and Ferrand concluded that orthography shapes spoken word recognition. These orthographic effects on spoken word recognition were subsequently replicated in different languages (Ventura, Morais, Pattamadilok, \& Kolinsky, 2004), in different populations (Miller \& Swick, 2003), with different orthographic manipulations (Ziegler, Muneaux, \& Grainger, 2003), and in a study with tight controls for phonetic differences between consistent and inconsistent words (Ziegler, Ferrand, \& Montant, 2004).

The goal of the present study was to investigate at what point during reading development spoken word recognition is affected. Surprisingly few studies have addressed this issue. Indeed, most studies on this topic have been conducted with skilled adult readers. However, it seems important to demonstrate that (1) orthographic effects in spoken word recognition are not present in beginning readers who have not yet acquired the alphabetic code and (2) orthographic effects develop only after children have become fluent readers. If the second prediction is correct, then dyslexic readers should show reduced orthographic effects on spoken word recognition because of their severe and long-lasting difficulties in acquiring the alphabetic code.

In the present experiment, orthographic neighborhood $(\mathrm{ON})$ and phonological neighborhood (PN) size effects were used as markers for orthographic and phonological processes. Neighborhood size is a similarity metric that indicates whether or not a word's orthography or phonology is similar to that of many other words in the mental lexicon (see, e.g., Coltheart, Davelaar, Jonasson, \& Besner, 1977). In an auditory lexical decision task and a shadowing task, 
Ziegler et al. (2003) manipulated ON and PN size orthogonally. They found that PN had an inhibitory effect on spoken word recognition. People found it harder to recognize words in dense neighborhoods than those in sparse neighborhoods (see also Cluff \& Luce, 1990; Goldinger, Luce, \& Pisoni, 1989; Luce \& Pisoni, 1998; Vitevitch \& Luce, 1998, 1999). Such inhibitory neighborhood density effects are typically taken to indicate lexical competition between phonologically similar words (see, e.g., Luce \& Pisoni, 1998).

In contrast to the inhibitory effect of phonological neighbors, Ziegler et al. (2003) also found a facilitatory effect of orthographic neighbors. That is, participants processed spoken words with many orthographic neighbors (e.g., WIPE) more quickly than words with few orthographic neighbors (e.g., TYPE). This effect suggests that spoken words with a common orthographic structure are processed more efficiently than spoken words with a less common orthographic structure.

In the present experiment, $\mathrm{ON}$ and $\mathrm{PN}$ size effects were used as developmental markers of the influence of written language on spoken word recognition. The predictions were straightforward: Beginning readers should show normal phonological competition effects but no orthographic facilitation. More advanced readers should show both phonological competition and orthographic facilitation. Finally, dyslexic children should show no orthographic facilitation and possibly abnormal phonological competition effects. Note that the dyslexic readers had the same chronological age as the advanced readers (to control for spoken language exposure) and the same reading age as the beginning readers (to control for written language exposure). In sum, we predicted that the size of the orthographic effects in spoken word recognition would be directly related to the children's experience and expertise with written language (i.e., their reading levels).

\section{METHOD}

\section{Participants}

All the children who participated in the experiment were monolingual French speakers with no known history of speech or hearing disorders. We tested 18 beginning readers ( 7.1 years, $S D=0.33$ ), 18 advanced readers $(11.4$ years, $S D=0.63)$, and 18 dyslexics $(11.4$ years, $S D=0.69)$. The advanced readers and dyslexics were matched for chronological age $[t(1,34)=1.29]$. Reading ability was measured using a standardized reading test (Lefavrais, 1965). The reading ages of the beginning readers and the dyslexics were 7.0 $(S D=0.56)$ and $7.1(S D=0.59)$ years, respectively. The reading age of the advanced readers was 11.7 years $(S D=0.86)$.

The dyslexic children all had IQs above 85 , no spoken language impairment, and no attention deficit hyperactivity disorder. These variables were assessed by an interdisciplinary team using a variety of standard test batteries (e.g., L2MA; Chevrie-Muller, Simon, \& Fournier, 1997)

\section{Stimuli and Design}

Sixty monosyllabic words were selected from a French lexical database for children (NOVLEX; Lambert \& Chesnet, 2001). Most of them were consonant-vowel-consonant (CVC) words. The words belonged to one of four groups that resulted from a factorial combination of PN and ON. ON was computed by counting the number of words that could be obtained by substituting a single letter at any position within the word (see, e.g., Coltheart et al., 1977). PN was computed by counting the number of words that could be obtained by substituting a single phoneme at any position within the word. In contrast to Luce and Pisoni's (1998) PN measure, phoneme omissions were not counted in the present study, so that the same metrics could be obtained for the computation of $\mathrm{ON}$ and of PN. A list of the word stimuli is presented in the Appendix, and item characteristics are given in Table 1.

Words in the four conditions were matched for word frequency taken from the NOVLEX database. An item-based ANOVA with frequency as the dependent variable and $\mathrm{ON}$ and $\mathrm{PN}$ as factors showed no significant main effects or interactions (all $F \mathrm{~s}<1$ ). We also double-checked the frequency matching using a more recent child database (MANULEX; Lété, Sprenger-Charolles, \& Colé, 2004) (all $F \mathrm{~S}<1$ ). The words were matched for uniqueness point, length (all had three phonemes), and auditory length (all $F_{\mathrm{S}}<1$ ). Finally, we calculated phonotactic probability, which has been shown to have a facilitatory effect on word recognition (see, e.g., Vitevitch \& Luce, 1998, 1999). Specifically, we calculated both positional segment frequency (i.e., how often a particular segment occurs in a given position in a word) and positional biphone frequency (i.e., segment-to-segment co-occurrence probability). The computations were identical to those described in Vitevitch and Luce $(1998,1999)$. Note that PN and phonotactic probability are naturally confounded: The more phonological neighbors a word has, the greater its phonotactic probability. Thus, it is not possible to match words with dense PNs and those with sparse PNs on phonotactic probability. However, words with dense and with sparse ONs were matched on phonotactic probability. An ANOVA with phonotactic probability as the dependent variable showed significant main effects for PN (phone frequency, $p<.005$; biphone frequency, $p<.0001$ ) but no significant effect for $\mathrm{ON}\left(\right.$ all $\left.F_{\mathrm{S}}<1\right)$ and no interactions between $\mathrm{ON}$ and $\mathrm{PN}($ all $F \mathrm{~S}<1)$

For the purpose of the lexical decision task, 60 nonwords were created that matched the words in terms of length. The nonwords were created by changing the initial, the medial, or the final phoneme of a

Table 1

Item Characteristics of Words Used in the Present Study

\begin{tabular}{cccccccc}
\hline Neighborhood & $\begin{array}{c}\text { Freq } \\
\text { (NOVLEX) }\end{array}$ & $\begin{array}{c}\text { Freq } \\
\text { (MANULEX) }\end{array}$ & PN & ON & $\begin{array}{c}\text { Phone } \\
\text { Prob }\end{array}$ & $\begin{array}{c}\text { Biphone } \\
\text { Prob }\end{array}$ & $\begin{array}{c}\text { Duration } \\
(\mathrm{msec})\end{array}$ \\
\hline PN+ON+ & 66.6 & 47.6 & 11.9 & 4.6 & .068 & .0080 & 603 \\
PN+ON- & 66.6 & 53.9 & 11.7 & 1.5 & .070 & .0089 & 601 \\
PN-ON+ & 66.5 & 63.9 & 5.9 & 4.3 & .056 & .0053 & 604 \\
PN-ON- & 66.0 & 74.1 & 5.7 & 1.5 & .054 & .0041 & 608 \\
\hline
\end{tabular}

Note-Freq, word frequency per million; $\mathrm{PN}+$, large phonological neighborhood; $\mathrm{PN}-$, small phonological neighbor hood; $\mathrm{ON}+$, large orthographic neighborhood; $\mathrm{ON}-$, small orthographic neighborhood; Phone Prob, position-specific phoneme probability; Biphone Prob, position-specific biphone probability. 
CVC word. All items were digitally recorded by a female French native speaker in a soundproof room on a digital audio recorder. The recordings were normalized and edited using a digital waveform editor.

\section{Procedure}

The children were tested individually in a quiet room. Stimuli were presented binaurally over headphones at a comfortable listening level. Stimulus presentation was controlled using DMDX software (Forster \& Forster, 2003). The children were asked to indicate as rapidly and as accurately as possible whether or not the auditorily presented stimulus was a real French word. The children gave their responses by pressing either the right-hand shift key for "yes" (oui) or the left-hand shift key for "no" (non) on the keyboard. Latencies were measured from the onset of the stimulus until the participant pressed the response key. The children received 12 practice trials. The experimental stimuli were presented in randomized order for each participant.

\section{RESULTS}

Raw data were cleaned according to the following procedure. First, latencies below $200 \mathrm{msec}$ or above 4,000 $\mathrm{msec}$ were removed ( $<1 \%$ of data per group). Next, latencies that were $3 S D$ s beyond the global mean for each group of participants were removed (beginning readers, $1.66 \%$; advanced readers, $1.36 \%$; dyslexics, $1.07 \%$ ). Three words were excluded due to the high error rates $(>40 \%)$ of the beginning readers. The exclusion of these items did not affect matching across conditions; in fact, these items had already been removed before the item characteristics given in Table 1 were calculated. Item durations were subtracted from individual response latencies. The results are presented in Table 2.

\section{Global Comparisons}

The overall pattern of results was as expected. All three groups showed an inhibitory PN effect (longer latencies for words with many phonological neighbors than for words with few phonological neighbors), whereas only the skilled readers showed a facilitatory ON effect (shorter latencies for words with many orthographic neighbors than for words with few orthographic neighbors). This pattern was assessed in an ANOVA that resulted from the factorial combination of group, PN, and ON. Because of large differences in overall response latencies across groups, the individual latency data were normalized using a $z$-score transformation (see Faust, Balota, Spieler, \& Ferraro, 1999).

The RT analysis exhibited a significant effect of PN $\left[F_{1}(1,53)=80.3, p<.0001 ; F_{2}(1,53)=3.0, p<.0001\right]$. The interaction between the effects of group and of PN was not significant (both $F_{\mathrm{S}}<1.2$ ). The effect of $\mathrm{ON}$ was significant by subjects $\left[F_{1}(1,53)=7.1, p<.01 ; F_{2}<1\right]$. More importantly, the interaction between the effects of group and of $\mathrm{ON}$ was significant by subjects $\left[F_{1}(2,53)=\right.$ $\left.5.2, p<.01 ; F_{2}(2,104)=1.5, p>.20\right]$. This interaction reflects the fact that the size of the $\mathrm{ON}$ effect varied across groups. No other effects reached significance apart from a significant interaction between $\mathrm{ON}$ and $\mathrm{PN}$ in the subjects analysis $\left[F_{1}(1,53)=10.5, p<.01 ; F_{2}<1.1\right]$. In the errors analysis, there were significant main effects of group $\left[F_{1}(2,53)=4.8, p<.01 ; F_{2}(2,98)=8.1, p<.01\right]$ and of $\mathrm{PN}\left[F_{1}(1,53)=8.5, p<.01 ; F_{2}(1,53)=2.4, p<.14\right]$. No other effects were significant. Below, we present the same analyses separately for each group using the nontransformed data.

\section{Advanced Readers}

The RT data exhibited an inhibitory effect of PN $\left[F_{1}(1,19)=56.9, p<.0001 ; F_{2}(1,53)=16.2, p<.0001\right]$, a facilitatory effect of ON $\left[F_{1}(1,19)=20.2, p<.0001\right.$; $\left.F_{2}(1,53)=4.7, p<.05\right]$, and no interaction between the effects of $\mathrm{ON}$ and of PN (all $F \mathrm{~s}<1$ ). In the error data, there was a significant main effect of $\mathrm{PN}\left[F_{1}(1,19)=6.6\right.$, $\left.p<.05 ; F_{2}(1,53)=4.0, p<.05\right]$. No other effects were significant (all $F \mathrm{~s}<1.3$ ).

\section{Beginning Readers}

The RT data showed an inhibitory effect for PN $\left[F_{1}(1,17)=18.6, p<.0001 ; F_{2}(1,53)=10.2, p<.002\right]$ and no significant effect for $\mathrm{ON}\left[F_{1}(1,17)=1.7, p>.20\right.$; $\left.F_{2}<1\right]$. The interaction between the effects of $\mathrm{ON}$ and of PN was significant in the analysis by subjects $\left[F_{1}(1,17)=\right.$ $\left.7.4, p<.02 ; F_{2}(1,53)=1.5, p>.20\right]$. This interaction reflects the fact that the facilitatory ON effect was present only in sparse PNs. In the error data, the PN effect approached significance by subjects $\left[F_{1}(1,17)=3.6\right.$, $\left.p<.10 ; F_{2}<1\right]$. No other effects were significant (all $F \mathrm{~s}<1)$

Table 2

Mean Lexical Decision Latencies (in Milliseconds) and Error Rates for Advanced Readers, Beginning Readers, and Dyslexics, and Main Effects of Neighborhood

\begin{tabular}{|c|c|c|c|c|c|c|c|c|c|c|c|c|}
\hline \multirow[b]{3}{*}{ Neighborhood } & \multicolumn{4}{|c|}{ Advanced Readers } & \multicolumn{4}{|c|}{ Beginning Readers } & \multicolumn{4}{|c|}{ Dyslexics } \\
\hline & \multicolumn{2}{|c|}{ RT } & \multicolumn{2}{|c|}{$\%$ Error } & \multicolumn{2}{|c|}{ RT } & \multicolumn{2}{|c|}{$\%$ Error } & \multicolumn{2}{|c|}{ RT } & \multicolumn{2}{|c|}{$\%$ Error } \\
\hline & $M$ & $\overline{S E}$ & $M$ & $S E$ & $M$ & $S E$ & $M$ & $S E$ & $M$ & $S E$ & $M$ & $S E$ \\
\hline $\mathrm{PN}+\mathrm{ON}+$ & 486 & 44 & 6.79 & 1.32 & 958 & 36 & 9.52 & 1.83 & 755 & 60 & 12.70 & 3.14 \\
\hline $\mathrm{PN}+\mathrm{ON}-$ & 522 & 41 & 5.33 & 1.33 & 935 & 37 & 11.85 & 2.06 & 721 & 66 & 8.52 & 1.85 \\
\hline $\mathrm{PN}-\mathrm{ON}+$ & 392 & 37 & 2.67 & 0.89 & 804 & 46 & 8.15 & 1.67 & 660 & 71 & 6.30 & 1.37 \\
\hline $\mathrm{PN}-\mathrm{ON}-$ & 446 & 35 & 4.23 & 1.04 & 873 & 39 & 8.97 & 1.79 & 683 & 79 & 9.83 & 2.62 \\
\hline PN main effect & \multicolumn{2}{|c|}{$-85^{* *}$} & \multicolumn{2}{|c|}{$-2.60^{* *}$} & \multicolumn{2}{|c|}{$-108^{* *}$} & \multicolumn{2}{|c|}{-2.13} & \multicolumn{2}{|c|}{$-66^{*}$} & \multicolumn{2}{|c|}{-2.54} \\
\hline ON main effect & \multicolumn{2}{|c|}{$+45^{* *}$} & \multicolumn{2}{|c|}{+0.06} & \multicolumn{2}{|c|}{+22} & \multicolumn{2}{|c|}{+1.58} & \multicolumn{2}{|c|}{-5} & \multicolumn{2}{|c|}{-0.32} \\
\hline
\end{tabular}

Note-PN+, large phonological neighborhood; $\mathrm{PN}-$, small phonological neighborhood; ON + , large orthographic neighborhood; ON-, small orthographic neighborhood. * ${ }^{*}$ ignificant by participants only $(p<.05) . \quad{ }^{* *}$ Significant by participants and items $(p<.05)$. 


\section{Dyslexic Readers}

The RT data exhibited an inhibitory effect of PN $\left[F_{1}(1,17)=4.8, p<.05 ; F_{2}(1,53)=3.5, p<.07\right]$. The PN effect was not significant in the error data $\left[F_{1}(1,17)=\right.$ $\left.1.5, p>.20 ; F_{2}(1,53)=1.4, p>.20\right]$. There was no hint of an ON effect in the dyslexic readers on either RTs or errors (all $F \mathrm{~s}<1)$. The interaction between the effects of ON and of PN was not significant on either RTs $\left[F_{1}(1,17)=2.9, p>.10 ; F_{2}(1,53)=1.8, p>.15\right]$ or errors $\left[F_{1}(1,17)=2.4, p>.10 ; F_{2}(1,53)=3.2, p>.07\right]$.

\section{Regression and Split-Half Analyses}

To show that the ON effect depends on reading level but the PN effect does not, we computed correlations between the size of each effect and the reading level of each group of children. This correlation was performed on the $z$-transformed normalized data. The results showed a significant positive correlation between the size of the ON effect and reading level $(r=.52, p<.0001)$. There was no significant correlation between the size of the PN effect and reading level $(r=-.24, p>.05)$.

Because the beginning readers showed a small trend toward an ON effect $(+22 \mathrm{msec})$, we suspected that interindividual differences might be particularly strong in Grade 1. Children in Grade 1 who are still struggling with basic decoding should not yet show an ON effect, whereas children who have already "cracked" the alphabetic code might show such an effect. To investigate this possibility, we split the group on the basis of reading performance. The 9 more advanced beginning readers showed an average facilitatory ON effect of $+69 \mathrm{msec}$, whereas the 9 less advanced readers showed an inhibitory ON effect of $-24 \operatorname{msec}[F(1,16)=12.1, p<.01]$. Furthermore, there was a significant positive correlation between the size of the ON effect and reading level for the children in Grade 1 $(r=.48, p<.05)$.

\section{DISCUSSION}

The present study had two major goals. First, we wanted to show that whereas phonological effects on spoken word recognition are already fully developed in beginning readers, orthographic effects develop only after children have become proficient readers. The results confirmed this prediction. PN effects were present in both beginning and advanced readers, whereas $\mathrm{ON}$ effects were present only in advanced readers. This finding shows that orthographic effects on spoken language are not artifacts of some uncontrolled spoken language property but reflect the influence of orthography on auditory word recognition.

Second, we wanted to show that the size of the ON effect varied as a function of reading expertise. This was accomplished by studying a group of dyslexic readers who were matched to the advanced readers in terms of age and, therefore, spoken language exposure. Even if some dyslexics overcome the phonological decoding problem, most will never acquire fully specified orthographic representations (Ziegler \& Goswami, 2005). Indeed, our results showed no ON effects for dyslexic children.
Regression analyses demonstrated a strong correlation between the size of the ON effect and reading skill not only for Grade 1 but for the entire sample. Furthermore, split-half analyses within the group of beginning readers demonstrated that only the more advanced beginners showed facilitatory ON effects. These data suggest that much of the "orthographic action" takes place during the first year of reading instruction.

How can we explain the facilitatory ON effect? As we have shown in previous work (Grainger, Muneaux, Farioli, \& Ziegler, 2005; Ziegler et al., 2003), words with many orthographic neighbors tend to have frequent and consistent sound-spelling relations. If word recognition involves a dynamic and interactive coupling between spoken and written words of various grain sizes (Frost \& Katz, 1989; Stone, Vanhoy, \& Van Orden, 1997; Van Orden \& Goldinger, 1994), then words with consistent sound-spelling relations would be advantaged over words with inconsistent sound-spelling relations. Such cross-code consistency has been identified as a core principle of visual and auditory word recognition (see Grainger \& Ziegler, in press).

It is also possible that learning to read and write contributes to the restructuring of phonological word representations during the initial years of schooling: Words with many orthographic neighbors would yield better phonological representations than words with few orthographic neighbors (Ziegler \& Goswami, 2005). Changes in the quality of phonological representations are often discussed in the context of lexical restructuring theory (LRT; Garlock, Walley, \& Metsala, 2001; Metsala \& Walley, 1998). According to LRT, lexical restructuring occurs in words with dense PNs. Words in dense regions are thought to go from holistic word form representations to more finely grained phoneme-based representations because the more coarsely grained holistic representations are no longer sufficient to distinguish among partially activated words.

A problem for explaining the facilitatory $\mathrm{ON}$ effect in terms of lexical restructuring is that the ON effect for our participants in Grade 1 was greater for words in sparse phonological regions than for words in dense phonological regions. Why would a word with a sparse PN, which is already easy to recognize auditorily, undergo lexical restructuring before a word in a dense PN? Clearly, this finding is inconsistent with the lexical restructuring view. One possibility would be that orthography is the factor that makes all words - not just those in sparse neighborhoods or those in dense ones - become phoneme-based representations. Although this idea cannot explain why the $\mathrm{ON}$ effect seems larger in dense phonological regions than in sparse ones, it is certainly consistent with the bigger picture that illiterates find it extremely difficult to delete a phoneme from a spoken word regardless of whether the word has many or few phonological neighbors (see, e.g., Morais et al., 1979).

In sum, although more work is needed to understand exactly how orthography interacts with spoken language, it seems quite clear that orthographic effects in spoken language are robust and vary as a function of reading ex- 
pertise. One side effect of literacy could be that it helps readers to specify phonological representations in order to overcome difficulties in speech perception in noisy environments. Indeed, in a recent study, Jamieson, Kranjc, Yu, and Hodgetts (2004) demonstrated a qualitative jump from relatively poor speech intelligibility in noise in kindergarten and Grade 1 to relatively good speech intelligibility in Grades 2 and 3. Obviously, one of the major changes between Grades 1 and 2 is the acquisition of literacy. Thus, it could be that learning to read plays an important role in phonological development.

\section{AUTHOR NOTE}

Correspondence concerning this article should be addressed to J. C. Ziegler, Laboratoire de Psychologie Cognitive, Pôle 3C, Case D, CNRS et Université de Provence, 3, place Victor Hugo, 13331 Marseille Cedex 3, France (e-mail: ziegler@up.univ-mrs.fr).

\section{REFERENCES}

Ben-Dror, I., Frost, R., \& Bentin, S. (1995). Orthographic representation and phonemic segmentation in skilled readers: A cross-language comparison. Psychological Science, 6, 176-181.

Castles, A., Holmes, V. M., Neath, J., \& Kinoshita, S. (2003). How does orthographic knowledge influence performance on phonological awareness tasks? Quarterly Journal of Experimental Psychology, 56A, 445-467.

Chéreau, C., Gaskell, M. G., \& Dumay, N. (2007). Reading spoken words: Orthographic effects in auditory priming. Cognition, 102, 341-360.

Chevrie-Muller, C., Simon, A. M., \& Fournier, S. (1997). Batterie langage oral, langage écrit, mémoire, attention (L2MA). Paris: Editions du Centre de Psychologie Appliquée.

Cluff, M. S., \& LuCE, P. A. (1990). Similarity neighborhoods of spoken two-syllable words: Retroactive effects on multiple activation. Journal of Experimental Psychology: Human Perception \& Performance, 16, 551-563.

Coltheart, M., Davelaar, E., Jonasson, J. T., \& Besner, D. (1977). Access to the internal lexicon. In S. Dornic (Ed.), Attention and performance VI (pp. 535-555). Hillsdale, NJ: Erlbaum.

Faust, M. E., Balota, D. A., Spieler, D. H., \& Ferraro, F. R. (1999). Individual differences in information-processing rate and amount: Implications for group differences in response latency. Psychological Bulletin, 125, 777-799.

Forster, K. I., \& Forster, J. C. (2003). DMDX: A Windows display program with millisecond accuracy. Behavior Research Methods, Instruments, \& Computers, 35, 116-124.

Frost, R., \& Katz, L. (1989). Orthographic depth and the interaction of visual and auditory processing in word recognition. Memory \& Cognition, 17, 302-310.

Garlock, V. M., Walley, A. C., \& Metsala, J. L. (2001). Age-ofacquisition, word frequency, and neighborhood density effects on spoken word recognition by children and adults. Journal of Memory \& Language, 45, 468-492.

Goldinger, S. D., Luce, P. A., \& Pisoni, D. B. (1989). Priming lexical neighbors of spoken words: Effects of competition and inhibition. Journal of Memory \& Language, 28, 501-518.

Grainger, J., Muneaux, M., Farioli, F., \& Ziegler, J. C. (2005). Effects of phonological and orthographic neighbourhood density interact in visual word recognition. Quarterly Journal of Experimental Psychology, 58A, 981-998.

Grainger, J., \& Ziegler, J. C. (in press). Cross-code consistency effects in visual word recognition. In E. L. Grigorenko \& A. Naples
(Eds.), Single-word reading: Biological and behavioral perspectives. Mahwah, NJ: Erlbaum.

Hallé, P. A., Chéreau, C., \& Segui, J. (2000). Where is the /b/ in "absurde" [apsyrd]? It is in French listeners' minds. Journal of Memory \& Language, 43, 618-639.

Jamieson, D. G., Kranjc, G., Yu, K., \& Hodgetts, W. E. (2004) Speech intelligibility of young school-aged children in the presence of real-life classroom noise. Journal of the American Academy of Audiology, 15, 508-517.

LAMberT, E., \& Chesnet, D. (2001). NOVLEX: Une base de données lexicales pour les élèves de primaire. L'Année Psychologique, 101, 277-288

Lefavrais, P. (1965). Test de l'Alouette. Paris: ECPA

Lété, B., Sprenger-Charolles, L., \& Colé, P. (2004). MANUlEX: A grade-level lexical database from French elementary school readers. Behavior Research Methods, Instruments, \& Computers, 36, 156-166.

Luce, P. A., \& Pisoni, D. B. (1998). Recognizing spoken words: The neighborhood activation model. Ear \& Hearing, 19, 1-36.

Metsala, J. L., \& Walley, A. C. (1998). Spoken vocabulary growth and the segmental restructuring of lexical representations: Precursors to phonemic awareness and early reading ability. In J. L. Metsala \& L. C. Ehri (Eds.), Word recognition in beginning literacy (pp. 89-120). Mahwah, NJ: Erlbaum.

Miller, K. M., \& Swick, D. (2003). Orthography influences the perception of speech in alexic patients. Journal of Cognitive Neuroscience, 15, 981-990.

Morais, J., Cary, L., Alegria, J., \& Bertelson, P. (1979). Does awareness of speech as a sequence of phones arise spontaneously? Cognition, 7, 323-331

Seidenberg, M. S., \& Tanenhaus, M. K. (1979). Orthographic effects on rhyme monitoring. Journal of Experimental Psychology: Human Learning \& Memory, 5, 546-554.

Slowiaczek, L. M., Soltano, E. G., Wieting, S. J., \& Bishop, K. L. (2003). An investigation of phonology and orthography in spokenword recognition. Quarterly Journal of Experimental Psychology, 56A, 233-262.

Stone, G. O., Vanhoy, M., \& Van Orden, G. C. (1997). Perception is a two-way street: Feedforward and feedback phonology in visual word recognition. Journal of Memory \& Language, 36, 337-359.

VAN ORden, G. C., \& Goldinger, S. D. (1994). Interdependence of form and function in cognitive systems explains perception of printed words. Journal of Experimental Psychology: Human Perception \& Performance, 20, 1269-1291.

Ventura, P., Morais, J., Pattamadilok, C., \& Kolinsky, R. (2004). The locus of the orthographic consistency effect in auditory word recognition. Language \& Cognitive Processes, 19, 57-95.

Vitevitch, M. S., \& Luce, P. A. (1998). When words compete: Levels of processing in perception of spoken words. Psychological Science, 9, 325-329.

Vitevitch, M. S., \& Luce, P. A. (1999). Probabilistic phonotactics and neighborhood activation in spoken word recognition. Journal of Memory \& Language, 40, 374-408.

Ziegler, J. C., \& FerRAND, L. (1998). Orthography shapes the perception of speech: The consistency effect in auditory word recognition. Psychonomic Bulletin \& Review, 5, 683-689.

Ziegler, J. C., Ferrand, L., \& Montant, M. (2004). Visual phonology: The effects of orthographic consistency on different auditory word recognition tasks. Memory \& Cognition, 32, 732-741.

Ziegler, J. C., \& Goswami, U. (2005). Reading acquisition, developmental dyslexia, and skilled reading across languages: A psycholinguistic grain size theory. Psychological Bulletin, 131, 3-29.

Ziegler, J. C., Muneaux, M., \& Grainger, J. (2003). Neighborhood effects in auditory word recognition: Phonological competition and orthographic facilitation. Journal of Memory \& Language, 48 , $779-793$. 


\begin{tabular}{|c|c|c|c|}
\hline \multicolumn{4}{|c|}{ APPENDIX } \\
\hline \multicolumn{4}{|c|}{$\begin{array}{c}\text { Table A1 } \\
\begin{array}{l}\text { Stimulus Words, by Phonological Neighborhood (PN) } \\
\text { and Orthographic Neighborhood (ON) }\end{array}\end{array}$} \\
\hline \multicolumn{2}{|c|}{$\mathrm{PN}+$} & \multicolumn{2}{|c|}{$\mathrm{PN}-$} \\
\hline $\mathrm{ON}+$ & $\overline{\mathrm{ON}-}$ & $\mathrm{ON}+$ & $\mathrm{ON}-$ \\
\hline pile & code & cube & ruche \\
\hline sage & nord & jupe & rhume \\
\hline gris & plat & nage & noce \\
\hline masse & face & gosse & mode \\
\hline botte & frais & lame & lutte* \\
\hline moule & gêne & rare & russe* \\
\hline roche & haine & lune & coude \\
\hline coupe & fesse & gomme & lampe \\
\hline vigne & bague & niche & mince \\
\hline boule & bulle & pince & mine \\
\hline reine & lisse & honte & vase \\
\hline mèche & laine & tasse & soupe \\
\hline hutte* & faute & ligne & vague \\
\hline panne & grain & poche & robe \\
\hline cache & soeur & signe & sens \\
\hline
\end{tabular}

Note-PN+, words with large PNs; PN-, words with small $\mathrm{PNs}$; ON+, words with large ONs; ON-, words with small

ONs. $\quad$ Excluded from the analysis because of high error rates.

(Manuscript received December 11, 2005;

revision accepted for publication May 3, 2006.) 